\title{
A Recording and Integrating Gas Calorimeter.
}

By Dr. J. S. G. Thomas, Senior Physicist, South Metropolitan Gas Company.

$\mathrm{U}^{\mathrm{N}}$ NDERTAKINGS operating under the provisions of the Gas Regulation Act 1920 , are required to deliver gas of a declared calorific value to consumers, and charges to individual consumers are to be based upon the value of the total thermal energy supplied to each. By calorific value is to be understood the number of B.Th.U. produced by the combustion of I cubic foot of gas measured at $60^{\circ} \mathrm{F}$. under a pressure of 30 inches of mercury and saturated with water vapour. Under the Act, penalties are to be inflicted upon the gas undertaking, if on any day for a period of two hours or more the calorific value of the gas supplied is more than 6 per cent. below the declared calorific value, or if in any quarter the average calorific value is less than the declared calorific value. Embodied in Orders under the Act are clauses governing the price per therm (I00,000 B.Th.U.) to be charged by individual gas undertakings, and the amount of dividend to be paid to proprietors, as regulated by this price. Such, in brief, are the main thermal clauses of the Gas Regulation Act r9zo-the Charter of Liberty of the gas industry in this country, and the consumers' guarantee that gas undertakings must and will " deliver the goods."

Accurate gas calorimetry has long been of importance for scientific purposes; extremely accurate gas calorimetry is now of consequence industrially and socially. The accuracy of determination desirable will be realised when it is understood that, in terms of money, an error of $x$ per cent. in respect of the thermal value of the annual gas supply of England, Scotland, and Wales represents about 500,000l.

Prof. C. V. Boys, at the annual meeting of the Institution of Gas Engineers on June 22, exhibited and described a recording and integrating calorimeter (Fig. I) which he has designed and constructed primarily to meet the requirements of the Act in the matter of continuously recording the calorific value of towns' gas. The instrument is, however, immediately applicable to the determination and recording of the calorific value and percentage variation with time of the calorific value of any gas. It is of the water-flow type, the same water being circulated continuously through the apparatus and cooled to atmospheric temperature, by the hot-air engine and cooling coil seen at the bottom left-hand side of the figure. This is an important consideration in continuous calorimetry, as with another form of recording gas calorimeter at present available the cost of water amounts to about $20 l$. per annum. The fundamental features of the instrument are: water and gas are doled out positively at the correct respective rates, and the correction for gas volume as affected by temperảture, pressure, and humidity are likewise effected by a positive operation.

Water Measurement and General.-Water flows from a tank, seen in the top right-hand corner of Fig. I, where the level is maintained constant, through a

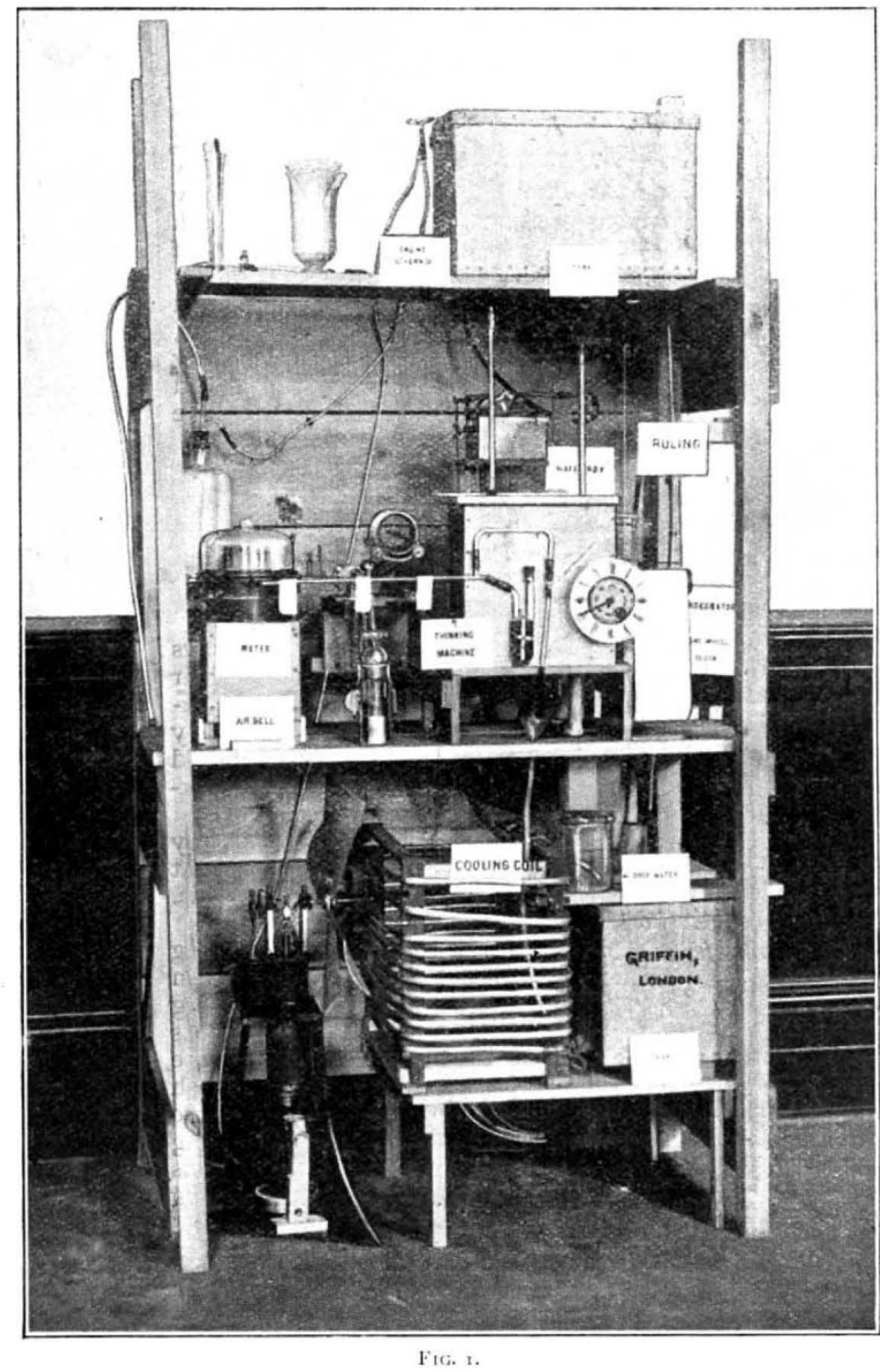

nozzle into a celluloid bucket pivotted eccentrically and so proportioned that it overbalances and empties into the celluloid water-box shown in Fig. I. After emptying and draining, the bucket is released by a clock every half-minute, and the operation is repeated. The quantity of water delivered to the bucket can be adjusted by a stop, so that if the gas is of the declared calorific value, the rise of temperature of the water flowing in the calorimeter is exactly $10^{\circ} \mathrm{C}$. On the record sheet, therefore, corresponding percentage No. 2755 , vOL. IIO] 
departures from the declared calorific value are strictly comparable, being represented by equal displacements of the recording point, whatever the declared calorific value.

The water doled out passes through a small hole into a second compartment of the water-box, and thence to the calorimeter proper. When the bucket is overturned, the jet of water misses the bucket and enters a third compartment of the water-box, whence it passes to a fourth compartment, to be delivered to a small celluloid water-wheel, which drives, through an elastic connection, the escapement of a one-wheel pendulum clock ticking half-seconds, and through an intervening mechanism-called by Prof. Boys the "thinking machine"-the axle of the gas meter.

The Gas Meter.-The gas meter is shown in vertical section in Fig. 2, the smallest arrow indicating the direction of entry of gas previously saturated with water vapour. The meter drum is of celluloid, and is provided with buoyancy chambers $\mathrm{A}$, so that the drum is largely carried by the water and not by the axle. The gas measured in any compartment is therefore contained

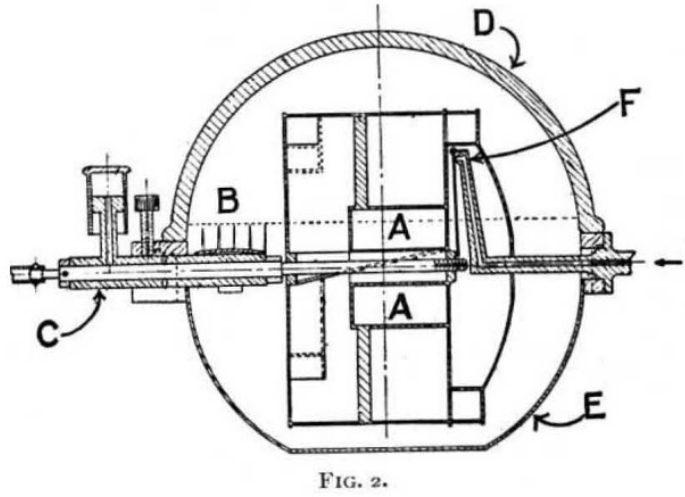

in a chamber of which the sides, ends, roof, and about two-thirds of the floor are independent of the waterlevel, which can be adjusted to $\frac{1}{10000}$ th inch by reference to the upturned points, $B$. Changes of waterlevel, even if they should occur, would clearly have little effect on the capacity of the meter. The meter drum rests loosely on the axle, which is screwed, so that if meter and axle turn at the same rate there is no endlong movement of the drum. The axle works in a long sleeve, C, screwed into a brass ring, and vaseline is forced in to make axle and sleeve water-tight. No stuffing boxes are employed, and the inlet and outlet aprons of the usual wet-meter drum are replaced by discs closing the front and back of the usual four compartments. The meter is enclosed gas-tight within a glass bell D above, and a spun copper bowl, $\mathrm{E}$, below. The pressure in the meter is about $\frac{1}{8}$ inch of water in excess of atmospheric, such excess being due to the inclusion in the gas circuit of a pin-hole burner to prevent the calorimeter burner being extinguished by the sudden slamming to of a door, etc.

The "Thinking Machine."-This device, already referred to, is shown in plan in Fig. 3A. It consists of a small ball-disc-cylinder integrator, a vertical section of which is shown in Fig. 3B, coupled with epicyclic double reduction gear, as shown at $\mathrm{A}$ in Fig. $3 \mathrm{~A}$, inserted between the clock and the meter axle so as to control the rate of revolution of the meter drum.
The epicyclic device gears down the motion of the disc of the integrator in the ratio $3: 2$, the disc itself being geared down from the water-wheel in the ratio $4: \mathrm{r}$. The motion of the cylinder of the integrator is geared down in the ratio $\mathrm{I}_{5}: \mathbf{I}$.

Temperature and pressure corrections to the gas volume are automatically and positively effected in the following way. It is clear that if the ball, $B$ (Fig. $3 \mathrm{~B}$ ), makes contact with the rotating disc, C,

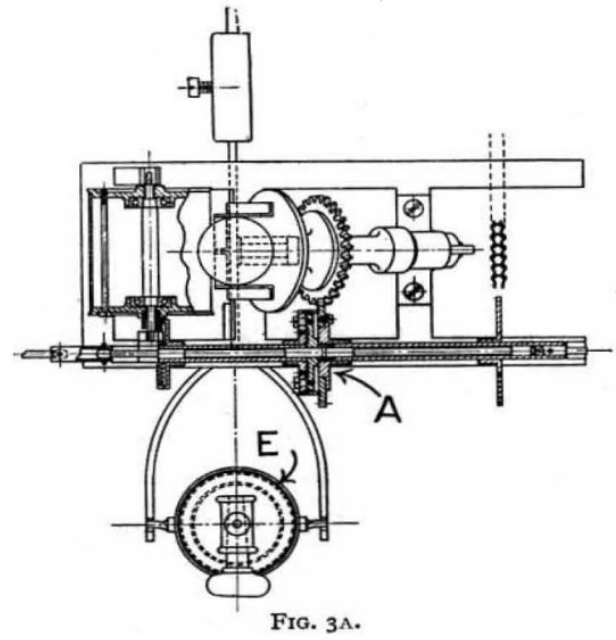

exactly at the centre of the disc, no rotary motion will be communicated by the disc to the ball and consequently none to the cylinder D. Such a position of the ball corresponds to normal conditions of temperature $\left(60^{\circ} \mathrm{F}\right.$.) and pressure ( 30 ins. of mercury) of the gas, and may be conveniently referred to as its N.T.P. position. The radial displacement of the ball from the centre of the disc is made to depend upon atmospheric temperature and pressure as follows: E (Fig. 3A) shows in plan a glass bell filled with air floating

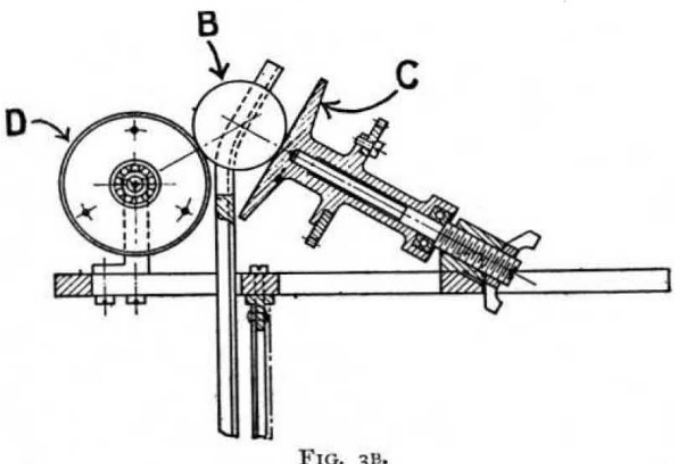

in a mercury and water seal, and connected by a lever system with a fork which displaces the ball to one side or other of the centre of the disc, according as the bell rises or falls with change of atmospheric conditions. The lever system is such that the ball moves I inch, equal to the radius of the cylinder, when the gas volume correction is ro per cent. Such displacement of the ball is accompanied by its rotation, producing rotation of the cylinder, $\mathrm{D}$, whereby endlong motion is communicated to the meter drum, resulting in the gas inlet to the meter, F, Fig. 2, being further closed or opened as required, so that the rate of gas delivery 
reduced to standard conditions is maintained constant to within $\frac{1}{10}$ per cent. The corrections effected over a period of a month are automatically recorded on a drum revolving above the device. The method of mounting the meter drum loose on a screwed axle also prevents the occurrence of accidents should the gas supply be temporarily cut off and resumed later, or should the water flow cease. The possible interference of a mouse with the righting of the bucket after emptying is also ingeniously provided for.

The Calorimeter Proper.--This is shown in vertical section in Fig. 4. A and B are the hot and cold water chambers respectively ; $\mathrm{C}$ is the heat interchanger, in which the heat of the products of combustion derived from gas burning at the fused-silica, burner, D, is communicated to the stream of water. A silica dome is disposed above the flame. The interchanger is made of sheet-lead closely folded into fifteen zig-zags round the central combustion space. Narrow up-cast water-ways are then formed on one side of the sheet, and down-cast gas-ways on the other side. The heated water passes to $B$ through the narrow neck in the double partition, E, a device introduced by Prof. Boys to prevent the calorimeter indicating more heat than is produced by the gas. The copper cylinder, F, fixed to the brass ring, $\mathrm{G}$, is so proportioned, that loss of heat from the upper part of the hot-water compartment is compensated by the equal gain from the cylinder lower down by the heat interchanger.

The operative thermometers, $\mathrm{H}$ and $\mathrm{J}$, are of brass, and are filled with amyl alcohol. They are closed with corrugated brass covers. A lever system utilising the third dimension of space, magnifies the deformation of the respective covers occurring with change of temperature, and the net difference of temperature of the two thermometers, due to heating, controls the position of an inked pen recording on a roll of paper, seen on the right of Fig. I, kept in motion by the clock. On the paper parallel lines are ruled during the rotation, indicating definite percentage departures of the actual measured calorific value of the gas from the declared calorific value. Time indications are in like manner impressed upon the record. An integrating device shown on the right of Fig. 4, operating after the manner of the Amsler planimeter and controlled by the position of the recording pen, averages the departures of the calorific value of the gas from the declared calorific value since

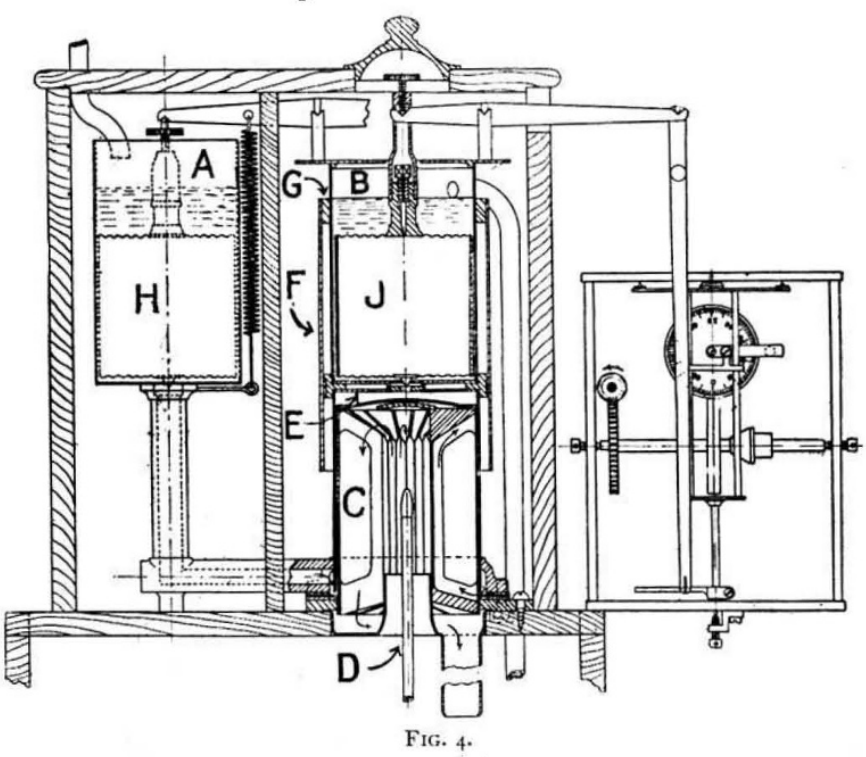

the indicator was last set to zero, i.e., since the beginning of the quarter, so that, for example, the integrator indicating +5 would signify a 5 -day $\mathrm{I}$ per cent. excess of calorific value, or a I-day 5 per cent. excess, etc.

The writer is extremely obliged to Prof. Boys for the kind manner in which he has afforded information concerning the instrument, and to Messrs. Griffin and Sons for providing the illustrations reproduced in this article.

\section{The Earth's "Crust" and its Composition.}

\section{By Thomas Crook.}

THE term "crust" is frequently used in dealing 1 with the constitution of the earth, but is seldom defined. It is a convenient scientific term to apply to the earth's outermost shell, the only portion of which geologists have much positive knowledge, and if it is put to scientific use, it should be defined, although a definition of it may involve some hypothesis as to the physical condition of the earth's interior.

According to Arrhenius, who assumes that the temperature-gradient observed in continental areas is persistent in depth, the temperature of the earth's interior greatly exceeds that of the critical temperature of the materials occurring there. He infers therefore that the interior is for the most part gaseous though rigid, and that this gaseous core is separated by a molten layer from an outer solid shell about 40 miles thick.
Osmond Fisher assumed a molten condition at a depth of 25 miles. To those who accept this view, the term "crust" has a very real and simple significance : it is the thin, solid, outer shell of the earth, underlain by molten magma.

At the present time, however, this hypothesis appears not to be widely held among geophysicists, most of whom follow Lord Kelvin, Sir George Darwin, and other eminent authorities who have shown good reasons for rejecting the hypothesis of a molten interior at such depths as postulated by Fisher and Arrhenius, and who claim that the earth is solid throughout. For those who adopt this view the definition of the earth's "crust" is a more difficult matter.

The prevalent view at the present day as regards the constitution of the earth's interior is that it consists of an inner core of nickel-iron about 6200 miles in 